Research on Multi-factor Forest Fire Prediction Model Using Machine Learning Method in

Yudong Li, ${ }^{1}$ Zhongke Feng, ${ }^{1}$ Ziyu Zhao, ${ }^{1}$ Shilin Chen, ${ }^{1}$ Hanyue Zhang, ${ }^{1}$

1 Precision Forestry Key Laboratory of Beijing, Beijing Forestry University, Beijing 100083,

China.

E-mail address :

Yudong Li : 1yd85842@163.com;

Zhongke Feng : zhongkefeng@bjfu.edu.cn

Ziyu Zhao : zhaozy0315@126.com; Shilin Chen: chenshilin@bjfu.edu.cn

Hanyue Zhang : hanyue.zhang@foxmail.com

Correspondence should be addressed to Zhongke Feng: zhongkefeng@ bjfu.edu.cn

Permanent address: Beijing Forestry University

(1)

[Manuscript]

\title{
Research on Multi-factor Forest Fire Prediction Model Using Machine Learning Method in China
}

Yudong Li, ${ }^{1}$ Zhongke Feng, ${ }^{1}$ Ziyu Zhao, ${ }_{1}^{1}$ Shilin Chen, ${ }^{1}$ Hanyue Zhang, ${ }^{1}$

171 Precision Forestry Key Laboratory of Beijing, Beijing Forestry University, Beijing 100083, China.

18 Correspondence should be addressed to Zhongke Feng: zhongkefeng@bjfu.edu.cn

19 Abstract 
21 important basis for preventing such fires. At present, there is little research on the prediction of long

22 time series forest fires in China. Choosing a suitable forest fire prediction model is of great importance

23 to China's forest fire prevention and control work. Based on data on fire hotspots, meteorology, terrain,

24 vegetation, infrastructure, and socio-economics collected from 2003 to 2016, we used a random forest

25 model as a feature-selection method to determine 13 major drivers of forest fires in China (such as

26 temperature, terrain etc.). The forest fire prediction models developed in this study are based on four

27 machine-learning algorithms: an artificial neural network, a radial basis function network, a

28 support-vector machine, and a random forest. The models were evaluated using the five performance

29 indicators of accuracy, precision, recall, f1 value, and area-under-the-curve value. We used the optimal

30 model to obtain the probability of forest fire occurrence in various provinces in China and create a

31 spatial distribution map of the areas with high incidences of forest fires. The results show that the

32 prediction accuracy of the four forest fire prediction models is between $75.8 \%$ and $89.2 \%$, and the

33 area-under-the-curve value is between 0.840 and 0.960 . The random forest model has the highest

34 accuracy $(89.2 \%)$ and area-under-the-curve value (0.96). It is used as the optimal model to predict the

35 probability of forest fire occurrence in China. The prediction results indicate that the areas with high

36 incidences of forest fires are mainly concentrated in northeastern China (Heilongjiang Province and

37 northern Inner Mongolia Autonomous Region), southeastern China (including Fujian Province and

38 Jiangxi Province) etc. In those areas at high risk of forest fires, the management departments can

39 improve the forest fire prevention and control by establishing watch towers and using other monitoring

40 equipment. This study not only helps in understanding the main drivers of forest fires in China, but it

41 also provides a reference for the selection of high-precision forest fire prediction models and provides a

42 scientific basis for China's forest fire prevention and control work. 
43 Keywords: forest fire occurrence in China; feature selection; forest fire driving factors; machine

44 learning; prediction model; forest fire prevention and control

\section{1. Introduction}

46 Forest fires are one of the most dangerous natural disasters. They have become the focus of worldwide

47 attention due to their rapid spread, their low controllability, and the hazards they pose[1-2]. Forest fires

48 have varying degrees of impact on human health and safety, the ecological environment and resources,

49 and society and the economy[3]. Forest fire prevention has therefore become a key research topic in the

50 fields of forestry and ecology[4-6].

51 The most effective way to control forest fires is to detect them quickly. Detection is usually divided

52 into three categories: satellite monitoring, smoke detection, and local perception (such as data analysis).

53 Satellite monitoring is expensive, involves delays, and is not fully applicable to all locations[7] . Smoke

54 detection also requires expensive equipment and maintenance work. In contrast, data for forest fire

55 analysis are easy to obtain, and data analysis is less expensive than the first two methods[8]. By

56 establishing a forest fire prediction model, we can predict the probability of the occurrence of a forest

57 fire and then strictly manage the area where the fire is likely to occur. This can directly reduce the

58 occurrence of forest fires and the potential casualties and economic losses[9-10]. This method is

59 therefore of great significance in forest fire prediction and prevention[11].

60 Much research has been conducted on forest fire prediction models. Logistic regression models are the

61 most commonly used. They have the advantage of solving the classification problem[12-16]. In recent

62 years, geographically weighted regression models have also been used. Wang[17]used a geographically

63 weighted regression model to predict regional fires in Gansu, China (2017). Guo[18] used a 
64 geographically weighted logistic regression model to determine the relationship between human-made

65 fires and the potential drivers of forest fires in northern China(2016). Such a method can provide a

66 reasonable explanation for spatial heterogeneity, but the regression analyses can only be performed on

67 continuous variables; the method lacks analysis of categorical variables. Liu [19] used an exponential

68 equation to predict the number of forest fires in China, but this model analyzed only meteorological

69 factors(2017). Similarly, many researchers have used generalized linear regression models for forest

70 fire prediction. Miao et al.[20] used the zero-inflated Poisson model to predict the frequency of forest

71 fires in Japan in 2000(2008). Mandallaz et al. [21] used the Poisson model to predict forest fires in

72 France, Italy, etc. (1997). Guo et al. [22] used ordinary least squares regression, zero-inflated negative

73 binomial regression and the zero-inflated negative binomial model to predict the number of forest fires

74 in the Greater Xing'an Mountains area of Heilongjiang Province, China, and demonstrated that the

75 zero-inflated negative binomial model has the best performance(2010).

76 The development of artificial intelligence has led researchers to focus on building a forest fire

77 prediction model using machine-learning algorithms[23-31]. Artificial neural networks consist of

78 neurons with adjustable connection weights. Compared with traditional multiple linear regression

79 models or parametric regression models, neural networks have better self-organization and

80 self-learning capabilities. They have been widely used in forest fire prediction[32-34]. For example,

81 Maeda et al.[35] used artificial neural networks and multi-temporal images from MODIS/Terra-Aqua

82 sensors to detect areas at high risk of forest fires in the Amazon region of Brazil(2009). The results

83 showed that the error is less than 1, and the predictions are accurate. Sakr et al. [36] predicted the

84 occurrence of forest fires in developing countries through two meteorological factors using artificial

85 neural networks (2011). 
A radial basis function $(\mathrm{RBF})$ neural network is a three-layer neural network. It is a special case of back

87 propagation neural network. At present, little research has used RBF neural networks for forest fire

88 prediction. Samaher[25] used an RBF neural network to predict the forest fire risk in Portuguese

89 natural parks (2018). The final root mean square error was 54.2.

90 Support-vector machines (SVM) are most suitable for binary classification of data in the form of

91 supervised learning. They apply the principle of structural risk minimization and have good learning

92 ability. In recent years, researchers have begun to use SVMs to predict forest fires[8][37-40]. Samaher

93 [25] used five different soft computing (SC) technologies, including an SVM algorithm, to predict

94 areas at risk of forest fires (2018). He determined that the SVM algorithm provides more accurate

95 prediction than the other four algorithms. Cortez et al. [8] used five different Data Mining(DM)

96 algorithms to predict the area at risk of forest fires in the northeastern region of Portugal (2007). Their

97 results showed that the root mean square error was 64.7. Based on Cortez's research, Zhiqing et

98 al.[7]used the semi-definite programming model to select the optimal kernel function of the SVM to

99 establish an SVM model for forest fire prediction (2012). The mean square error was 1.76, and the

100 model effect was good.

101 The random forest (RF) algorithm is a well-known integrated learning algorithm. It can provide higher

102 accuracy than other algorithms. At present, the use of RFs to predict forest fires is relatively

103 established[41-43]. Liang et al. [44] used an RF model to predict the occurrence of forest fires in Fujian

104 Province, China, with an accuracy rate of $85 \%$ (2016). Pourtaghi et al. [45] used an RF algorithm to

105 study the sensitivity of forest fires in Golestan Province, Iran. Their results showed that the model

106 achieves the desired accuracy (2016). 
109 changes and influencing factors of forest fires in specific years[46-50]. The results of previous research

110 are therefore localized and limited, and there is a lack of research into the most suitable and

111 high-precision forest fire prediction model on the national scale.

112 In this study, we selected a variety of forest fire driving factors to build four prediction models based

113 on machine-learning algorithms. The models were evaluated using data on Chinese forest fires from

1142003 to 2016 . The study has three objectives: (1) identify the main forest fire driving factors and their

115 impact in China; (2) select the most suitable model for forest fire prediction in China by creating four

116 models and comparing and analyzing the fitting results; and (3) use the model that offers the most

117 accurate predictions to create a probability map of forest fires in China and put forward

118 recommendations for forest fire prevention.

\section{2. Materials and Methods}

\section{$120 \quad$ 2.1 Study Area and Data Resources}

121 Located in east Asia on the west coast of the Pacific Ocean, China's territory is vast, with a total land

122 area of about 9.6 million square kilometers. The topography is high in the west, with vast mountains

123 and plateaus, and low in the east. The distance between the east and the west of the country is about

1245,000 kilometers; the coastline of the mainland is more than 18,000 kilometers in length; and the

125 temperature and precipitation are diverse, forming a variety of climates[51]. The distribution of forest

126 resources in China is uneven, being mainly distributed in the northeast, south, and southwest regions.

127 The forested area is 220 million hectares, and the forest coverage rate is $22.96 \%$. 
128 The research data were divided into six parts: fire ignition data, meteorological data, terrain data,

129 vegetation data, infrastructure data, and socio-economic data. The fire point data were derived from

130 NASA's Global Fire Atlas with Characteristics of Individual Fires, 2003-2016 (https://daac.ornl.gov/).

131 The Global Fire Atlas is a global dataset that tracks the daily dynamics of single fires. For each

132 individual fire, the dataset provides information about the fire's timing and location, scale, perimeter,

133 duration, speed, and direction of spread. These individual fire characteristics are based on the Global

134 Fire Atlas algorithms and estimated combustion day information from a 500-meter resolution product

135 of the 6 MCD64A1 combustion zone product of the Medium Resolution Imaging Spectroradiometer

136 (MODIS) collection.

137 This study used the fire point data for forest land in China from 2003 to 2016. The final number of fire

138 point data are 32746 (except Taiwan). The meteorological data are derived from the 14-day daily value

139 dataset of the China Meteorological Data Network (http://data.cma.cn/dataService/). The dataset

140 includes eight elements, such as the barometric pressure, temperature, relative humidity, and

141 precipitation of the station. Digital elevation model data were obtained through the Geospatial Data

142 Cloud website (http://www.gscloud.cn/). Vegetation data were represented by the normalized difference

143 vegetation index (NDVI), and the spatial distribution dataset of China's Quarterly Vegetation Index

144 comes from the Resource and Environment Data Cloud Platform (http://www.resdc.cn/). The basic

145 geographic data were taken from the "National Basic Geographic Database of 1:1 Million" on the

146 website of the National Geographic Information Resources Directory System. The data include the

147 locations of railways, highways, water systems, and residential areas. The socio-economic data include

148 population density and GDP per capita, and the grid data of the spatial distribution of population and

149 GDP were obtained from the Resource and Environment Data Cloud Platform. Figure 1 shows the map 


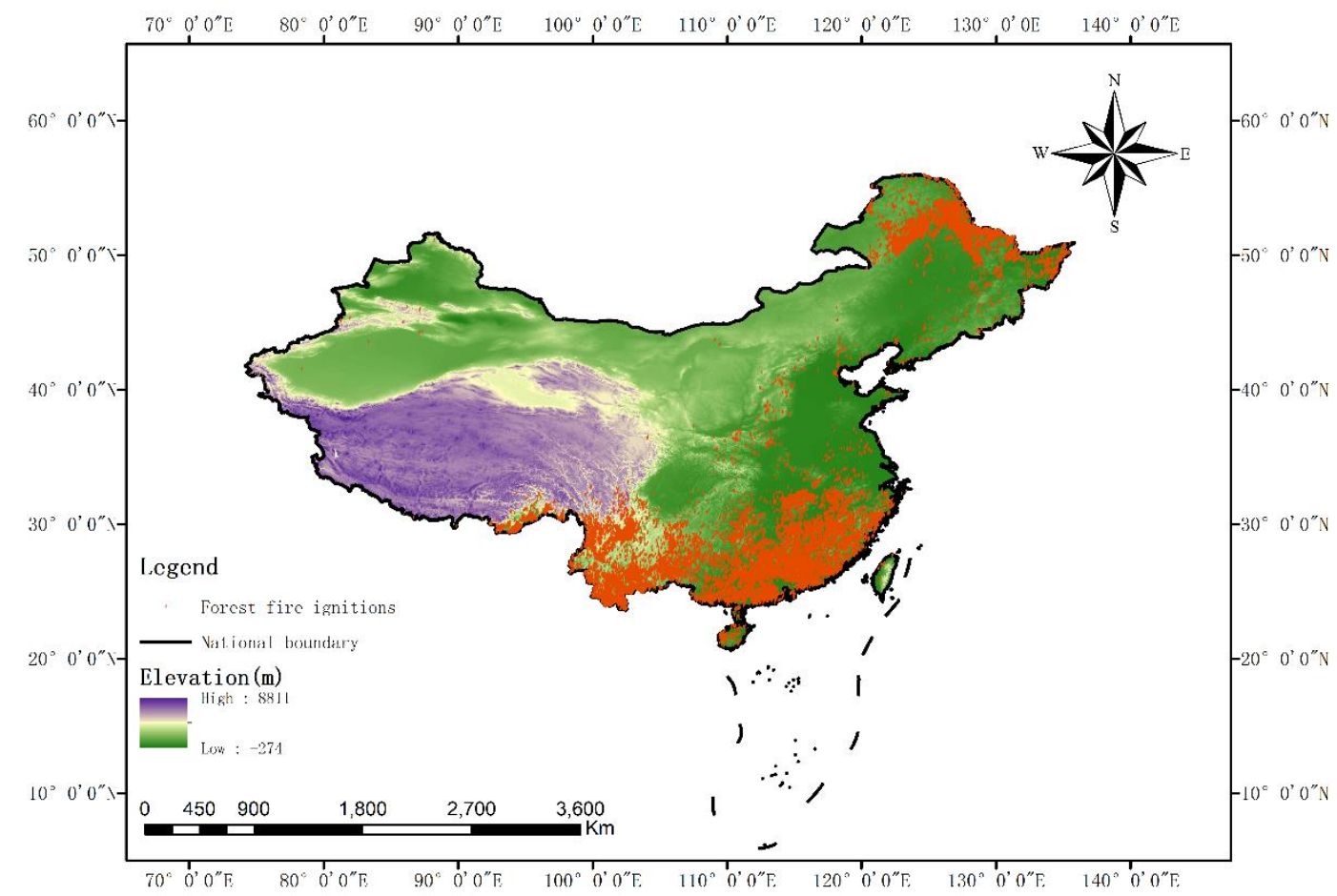

\subsection{Data Preprocessing}

\section{$154 \quad$ 2.2.1 Variable Handling}

155 The dependent variable is a binary variable (i.e., whether a forest fire occurs), and so we used ArcGIS to create a certain percentage of random points (non-fire points) and assigned 1 to fire points and 0 to non-fire points[52]. To ensure that the data were not over-dispersed, random points were selected according to experience in a ratio of 1:1[53], and, in principle, randomness in space and time should be

161 We obtained a total of 65,492 fire points and random points. 
162 For the meteorological data, we first used the ArcGIS 10.4 software to match the sample points with

163 the nearest meteorological station through the Thiessen polygon method. We then extracted the

164 corresponding sample point weather data and used a SQL Server database to match the daily weather

165 data. For the terrain data, we used the spatial analysis tool in the ArcGIS 10.4 software to extract the

166 slope and aspect of the obtained digital elevation model data. Seasonal climatic differences have an

167 impact on vegetation status, and so we divided the year into spring (March, April, May), summer (June,

168 July, August), autumn (September, October, November), and winter (December, January, February)

169 [55-56]. We used the extraction and analysis tools of the ArcGIS software to extract NDVI data for the

170 sample points on an annual and quarterly basis.

171 Similarly, from the infrastructure data and socio-economic data, we extracted the information

172 corresponding to the sample points. We set the aspect and special festivals as categorical variables, and

173 the others as continuous variables. Table 1 shows the classification of aspect [57]. During certain

174 traditional festivals in China, people burn paper to commemorate their loved ones, which raises the

175 probability of a forest fire. We included as special festivals (value 1) the following dates: Chinese New

176 Year's Eve, the first day of the first lunar month, the second day of the first lunar month, the fifteenth

177 day of the first lunar month, and Qingming Festival and Zhongyuan Festival (July 15th of the lunar

178 calendar). Non-special festivals were set to 0.

179

Table 1: Descriptions of aspect classifications

\begin{tabular}{ccc}
\hline Aspect & Azimuth (degree) & Classification \\
\hline Gentle slope & -1 & 0 \\
Shady slope & $0 \sim 67.5,337.5 \sim 360$ & 1
\end{tabular}


Semi-shady slope

Sunny slope

Semi-sunny slope
$67.5 \sim 112.5,292.5 \sim 337.5$

$157.5 \sim 247.5$

$112.5 \sim 157.5,247.5 \sim 292.5$
2

180 After processing, we obtained 20 independent variables and their possible values (see Table 2). Finally,

181 we performed data cleaning on the sample points and the various types of data extracted to remove

182 abnormal samples from the original dataset (including some samples with missing data and samples

183 with observations that were significantly outside the normal range).

184

Table 2: Descriptions of independent variables

\begin{tabular}{|c|c|c|c|}
\hline Category & Independent Variable & Symbol & Variable Type \\
\hline \multirow[t]{2}{*}{ Location } & Longitude $\left(^{\circ}\right)$ & Lon & Continuous Variable \\
\hline & Latitude $\left({ }^{\circ}\right)$ & Lat & Continuous Variable \\
\hline \multirow[t]{3}{*}{ Terrain } & Altitude (m) & Alt & Continuous Variable \\
\hline & Slope $\left(^{\circ}\right)$ & Slo & Continuous Variable \\
\hline & Aspect & Asp & Categorical Variable \\
\hline \multirow[t]{8}{*}{ Meteorology } & Average surface temperature $\left({ }^{\circ} \mathrm{C}\right)$ & Avst & Continuous Variable \\
\hline & $\begin{array}{l}\text { Daily maximum surface temperature } \\
\qquad\left({ }^{\circ} \mathrm{C}\right)\end{array}$ & Mast & Continuous Variable \\
\hline & Cumulative precipitation at $20-20(\mathrm{~mm})$ & Pre & Continuous Variable \\
\hline & Average relative humidity (\%) & Arh & Continuous Variable \\
\hline & Hours of sunshine (h) & Suh & Continuous Variable \\
\hline & Average temperature $\left({ }^{\circ} \mathrm{C}\right)$ & Ate & Continuous Variable \\
\hline & Daily maximum temperature $\left({ }^{\circ} \mathrm{C}\right)$ & Mate & Continuous Variable \\
\hline & Average wind speed $(\mathrm{m} / \mathrm{s})$ & Aws & Continuous Variable \\
\hline
\end{tabular}




\begin{tabular}{|c|c|c|c|}
\hline & Maximum wind speed (m/s) & $M w s$ & Continuous Variable \\
\hline \multirow[t]{2}{*}{ Infrastructure } & Distance from fire point to highway (m) & Hig & Continuous Variable \\
\hline & $\begin{array}{c}\text { Closest distance from fire point to } \\
\text { residential area }(\mathrm{m})\end{array}$ & Set & Continuous Variable \\
\hline \multirow[t]{3}{*}{ Social humanity } & Population & Pop & Continuous Variable \\
\hline & GDP & $G D P$ & Continuous Variable \\
\hline & Special festival & Sfe & Categorical Variable \\
\hline Vegetation & NDVI & $N D V I$ & Continuous Variable \\
\hline
\end{tabular}

\subsubsection{Data Normalization}

186 Given the different dimensions and magnitudes of the factors above, the data were normalized to

187 eliminate the variation in dimensions, avoid large differences in the magnitudes of the input and output

188 data, and balance the contributions of various factors. All the data were converted to between 0 and 1.

189 Table 3 shows the normalized formulas and specific interpretations of the independent variables.

\begin{tabular}{|c|c|c|c|}
\hline No. & Formula & Explanation & $\begin{array}{l}\text { Variables using this } \\
\text { formula }\end{array}$ \\
\hline (1) & $x_{i}^{*}=\frac{x_{i}-x_{\min }}{x_{\max }-x_{\min }}$ & $\begin{array}{c}x_{i} \text { and } x_{i}^{*} \text { are the values before and after data } \\
\text { normalization; } x_{\max } \text { and } x_{\min } \text { are the } \\
\text { maximum and minimum values of the full } \\
\text { sample data. }\end{array}$ & $\begin{array}{l}\text { Lon, Lat, Alt, Avst, } \\
\text { Mast, Pre, Suh, Ate, } \\
\text { Mate, Aws, Mws, Hig, } \\
\text { Set, Pop, GDP }\end{array}$ \\
\hline (2) & $x_{\alpha}=\sin \alpha$ & $\alpha$ is the slope value & Slo \\
\hline (3) & $x_{\gamma}=\frac{\gamma}{100}$ & $\gamma$ is the humidity value & Arh \\
\hline
\end{tabular}




\section{$191 \quad 2.3$ Research Method}

192

193

194

195

196

197

198

199

\subsubsection{Artificial Neural Networks}

Artificial neural networks (ANN) have become widely used in feedforward networks due to their clear structure, fast operation, easy implementation, and abilities for self-learning and adaption to the environment [24][58-59]. ANNs consist of three parts: an input layer, an output layer, and a hidden layer. The hidden layer may be a topological structure of one or more layers, as shown in Figure 2. The input layer does not perform any calculations. It is used to receive data; that is, to transfer data to the adjacent hidden layer with different weights. The hidden layer processes the data through a nonlinear activation function and then passes it to the output layer. The final result is obtained from the output layer [60]. The mathematical principle is as follows:

$$
\left\{\begin{array}{l}
\mathrm{h}^{(1)}=\varphi^{(1)}\left(\sum_{i=1}^{n} x_{i} \cdot \omega_{j}^{(1)}+b^{(1)}\right. \\
y=\varphi^{(2)}\left(\sum_{j=1}^{n} h_{i}^{(1)} \cdot \omega_{j}^{(2)}+b^{(2)}\right.
\end{array}\right.
$$

In the formula, input layer $x \in R^{m}$, hidden layer output $\mathrm{h} \in R^{n}$, output layer $y \in R^{K}$, input layer to hidden layer weight connection matrix $\omega^{(1)} \in R^{m \times n}$, the weight connection bias from the input layer to the hidden layer $b^{(1)} \in R^{n}$, the weight connection matrix and the bias from the hidden layer to the output layer are $\omega^{(2)} \in R^{n \times K}$ and $b^{(2)} \in R^{n \times K}$. 


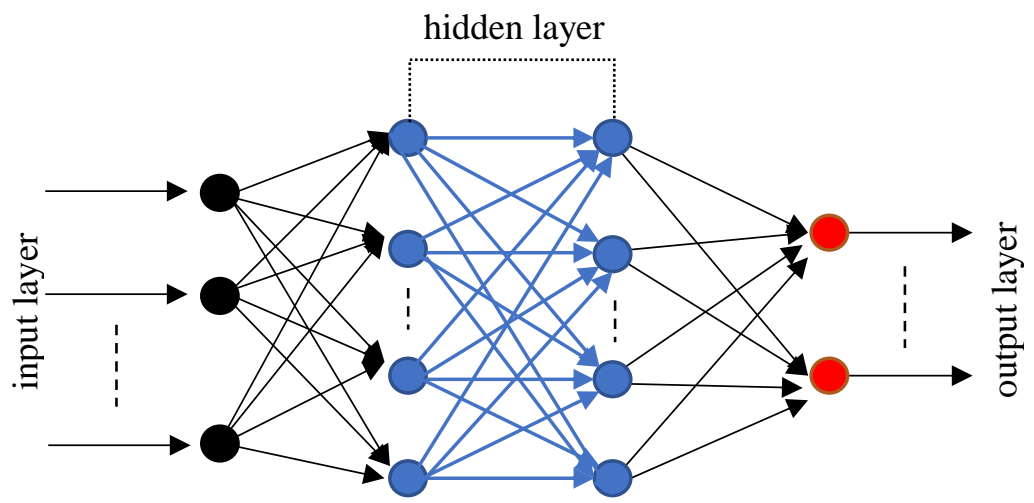

\subsubsection{Radial Basis Function Neural Network}

The radial basis function (RBF) neural network structure is a feedforward structure with an input layer, convergence speed, which can approximate any nonlinear function. It has been widely used in time-series forecasting, nonlinear control systems, and the graphics-processing field. The basic idea of an RBF network is as follows. The RBF is used as the "base" of the hidden unit to form the hidden layer space. The hidden layer transforms the input vector and transforms the low-dimensional pattern input data into the high-dimensional space. The result is that the data are linearly separable in the high-dimensional space. The output of the RBF neural network is:

$$
y_{i}=\sum_{i=1}^{h} \omega_{i j} \exp \left(-\frac{1}{2 \sigma^{2}}\left\|x_{p}-c_{i}\right\|^{2}\right) \quad j=1,2, \cdots, n
$$

where $x_{p}=\left(x_{1}{ }^{p}, x_{2}{ }^{p}, \cdots, x_{m}{ }^{p}\right)^{T}$ is the $p^{\text {th }}$ input sample $(\mathrm{p}=1,2,3, \ldots, \mathrm{P}), P$ is the total number of samples, $c_{i}$ is the center of the hidden layer node of the network, $\omega_{i j}$ is the connection weight from the hidden layer to the output layer, $i=1,2,3, \ldots, \mathrm{h}$ is the number of hidden layer nodes, $y_{i}$ is the actual output of the $j^{\text {-th }}$ output node of the network corresponding to the input sample [62]. 


\subsubsection{Support-Vector Machines}

223 Support-vector machines (SVM) are mainly used for pattern classification and nonlinear regression.

224 They are general learning algorithms based on the principle of structural risk minimization. The core 225 idea of SVMs is to establish a classification hyperplane as a decision surface to maximize the isolation 226 edge between the positive and negative examples, thereby providing a high generalization 227 performance[63]. SVMs can improve the ability to transform data from high-dimensional spaces by 228 flexibly using kernel functions when dealing with various nonlinear problems. Taking a two-class SVM as an example, given a training set $T=\left\{\left(x_{1}, y_{1}\right), \cdots\left(x_{l}, y_{l}\right)\right\} \in(X \times Y)^{l}$, where $x_{i} \in X=R^{n}, y_{i} \in$ $\{1,-1\}(i=1,2, \cdots l), x_{i}$ is the feature vector. The penalty parameter $C$ and the kernel function

$231 K\left(x, x^{\prime}\right)$ are first selected, and the optimization problem is then constructed and solved as follows [62]:

$$
\min _{\alpha} \frac{1}{2} \sum_{i=1}^{j} \sum_{j=1}^{l} y_{i} y_{j} a_{i} a_{j} K\left(x, x^{\prime}\right)-\sum_{j=1}^{l} \alpha_{j}
$$

$$
\text { s.t. } \sum_{i=1}^{l} y_{i} \alpha_{i}=0,0 \leq \alpha_{i} \leq C, i=1, \cdots, l
$$

234 The optimal solution is then obtained: $\alpha^{*}=\left(\alpha_{1}{ }^{*}, \cdots, \alpha_{l}{ }^{*}\right)^{T}$. A positive component of $\alpha^{*}: 0 \leq \alpha_{j}{ }^{*} \leq C$

235 is then selected, and the threshold is calculated as follows:

$$
b^{*}=y_{j}-\sum_{i=1}^{l} y_{i} \alpha_{i} K\left(x_{i}-x_{j}\right)
$$

237 Finally, the decision function is constructed:

$$
f(x)=\operatorname{sgn}\left(\sum_{i=1}^{l} \alpha_{i}^{*} y_{i} K\left(x, x_{i}\right)+b^{*}\right.
$$

\subsubsection{Random Forest}

A random forest is a highly flexible machine-learning algorithm with wide application prospects. In 
241 essence, an RF is a classifier consisting of multiple decision trees formed by random methods. These

242 trees are not related, hence its alternative name: "random decision tree." When the test data enter the

243 RF, each decision tree is classified, and the category with the most classification results among all the

244 decision trees is taken as the final result. The RF algorithm has the following advantages: it evaluates

245 the importance of each feature in classification problems, it can process input samples with

246 high-dimensional features, and it does not require a reduction in dimensionality. The method is as

247 follows.

248 Let $N$ be the number of attributes of the sample. $n$ is an integer greater than 0 and less than $N$. First, the

249 bootstrap method is used for resampling, randomly generating $M$ training sets S1, S2, ...SM. The

250 decision tree $\mathrm{A} 1, \mathrm{~A} 2, \ldots \mathrm{AM}$ corresponding to each training set is then generated. Before selecting the

251 attribute in each non-leaf node, $n$ attributes are randomly selected from the $N$ attributes as the split

252 attribute set of the current node, and the node is split in the best split mode among the $n$ attributes. Each

253 tree grows intact without pruning. For the test set sample $X$, each decision tree is used to test and obtain

254 the corresponding categories $\mathrm{C} 1(\mathrm{X}), \mathrm{C} 2(\mathrm{X}), \ldots \mathrm{CM}(\mathrm{X})$. Finally, the voting method is adopted, and the

255 category with the most output among the $M$ decision trees is regarded as the category to which the test

256 set sample $X$ belongs [62].

\section{$257 \quad$ 2.3.5 Model Performance Evaluation}

258 In this study, we used five performance indicators: accuracy, precision, recall, f1 value, and

259 area-under-the-curve (AUC) value to evaluate the performance of the models. Descriptions of the five 260 indicators are given below.

261 1. Accuracy: the proportion of the number of samples (TP and TN) that are correctly predicted to the 
total number of samples. The formula is as follows:

$$
P=\frac{T P+T N}{T P+F P+T N+F N}
$$

264 2. Precision: characterizes the classification effect of the classifier, which is the correct frequency value

265 predicted in the instance of the positive sample:

$$
T=\frac{T P}{T P+F P}
$$

267 3. Recall: characterizes the recall effect of a certain class. It is the correct frequency of prediction in the instance of the label as the positive sample:

$$
R=\frac{T P}{T P+F N}
$$

$$
\mathrm{f} 1=\frac{\left(1+a^{2}\right) P R}{a^{2}(P+R)}
$$

272 5. A ROC (receiver operating characteristic) curve is a method to judge the prediction effect of the

273 model[63]. The prediction accuracy of the model is judged by the value of the area under the curve

274 (AUC). The AUC ranges from 0.5 to 1. The larger the value, the closer the fit of the model.

275 Note: TP, FN, FP, TN in the formulas are the labels of the confusion matrix form of the output result.

276 The form is shown in Table 4:

\begin{tabular}{cc}
\hline Prediction (column) / label & Positive sample \\
(row)
\end{tabular}




\begin{tabular}{lll} 
Positive sample & TP & FN \\
Negative sample & FP & TN \\
\hline
\end{tabular}

\section{Results}

279 In this study, we used the MATLAB (MathWorks, USA, MATLAB 2019a) [58] and RStudio (JJ Allaire,

280 RStudio-1.2.5042/R 3.6.3) programming languages to implement the algorithms. We used MATLAB to

281 build the SVM, ANN, and RBFN models and used RStudio to build the RF models.

282 To evaluate feature factors and model performance issues, the dataset was divided into two parts by

283 randomly selecting $70 \%$ of the preprocessed sample data as the training set and $30 \%$ as the test set [59].

\section{$284 \quad$ 3.1 Feature Selection}

285 We used the RF algorithm to perform feature selection on all variables after preprocessing, and we

286 selected the subset of features that have the greatest impact on the dependent variable for the next

287 model-building process. We divided the full sample according to the above-mentioned proportions (70\%

288 of the training set and $30 \%$ of the test set), and we obtained five training samples after repeating the

289 process five times. Then we used the varSelRF package in the $\mathrm{R}$ language to perform feature variable

290 selection calculations on the five training samples to obtain the variable subsets of the five intermediate

291 models. Finally, we chose the variables that appeared 3 times or more in the five variable subsets as the

292 main forest fire driving factors to enter the model fitting process. Table 5 shows the results of feature

293 selection.

\begin{tabular}{|c|c|c|c|c|c|c|c|}
\hline No. & Variable & Sample 1 & Sample 2 & Sample 3 & Sample 4 & Sample 5 & Frequency \\
\hline
\end{tabular}




\begin{tabular}{|c|c|c|c|c|c|c|c|}
\hline 1 & Lat & + & + & + & + & + & 5 \\
\hline 2 & Lon & + & + & + & + & + & 5 \\
\hline 3 & Avst & + & + & + & + & + & 5 \\
\hline 4 & Mast & + & + & & + & + & 4 \\
\hline 5 & Pre & + & + & & + & + & 4 \\
\hline 6 & Arh & + & + & + & + & + & 5 \\
\hline 7 & Suh & + & + & + & + & + & 5 \\
\hline 8 & Ate & + & + & + & + & + & 5 \\
\hline 9 & Mate & + & + & + & + & + & 5 \\
\hline 10 & Aws & & & & & & 0 \\
\hline 11 & Mws & & & & & & 0 \\
\hline 12 & Alt & + & + & + & + & + & 5 \\
\hline 13 & Slo & & & & & & 0 \\
\hline 14 & Asp & & & & & & 0 \\
\hline 15 & Set & & & & & & 0 \\
\hline 16 & Hig & & & & & & 0 \\
\hline 17 & GDP & + & + & & + & + & 5 \\
\hline 18 & Pop & + & + & + & + & + & 5 \\
\hline 19 & NDVI & + & + & + & + & + & 5 \\
\hline 20 & Sfe & & & & & & 0 \\
\hline
\end{tabular}

295 The results show that the main influencing variables are longitude, latitude, average surface

296 temperature, daily maximum surface temperature, accumulated precipitation, average relative humidity,

297 sunshine hours, average temperature, daily maximum temperature, altitude, population, GDP, and

298 NDVI. These variables performed subsequent model fitting. Then the mean decrease accuracy obtained 


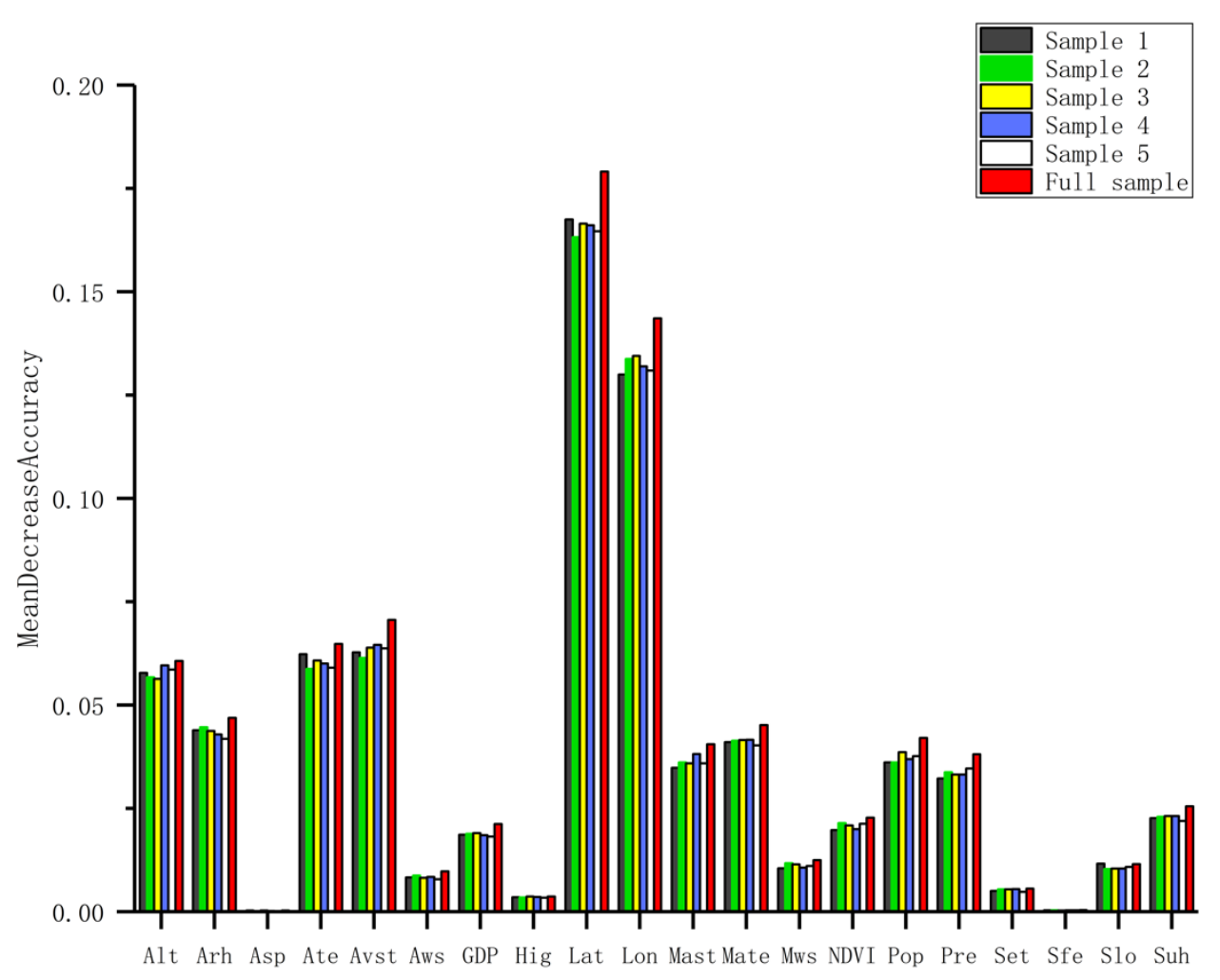
occurrence of forest fires. Thus, the location factor has the most influence on the occurrence of forest fires. In addition, altitude also affects the occurrence of forest fires. The second greatest influence is the temperature factor (average surface temperature and average temperature), reflecting the fact that high temperatures can cause fires. Meteorological factors, including rainfall, sunshine hours, and average relative humidity, can cause forest fires to varying degrees. Human activities (GDP and population) and vegetation coverage also have an influence on the occurrence of forest fires but less so than other

311 factors such as weather and location. The variables not selected by the RF algorithm include average 
wind speed, maximum wind speed, aspect, slope, the closest distance from the fire point to the highway,

313 the closest distance from the fire point to a residential area, and special festivals. The results indicate

314 that these seven variables have little influence on the occurrence of forest fires during the data analysis.

\section{$315 \quad 3.2$ Model Fitting Results}

\section{$316 \quad 3.2 .1$ Artificial Neural Network}

317 The input layer of the ANN consists of 13 neurons after feature selection: Lat, Lon, Avst, Mast, Pre,

318 Arh, Suh, Ate, Mate, Alt, GDP, Pop, and NDVI. The output layer contains two units (1 or 0). We used

319 gradient descent to optimize the algorithm. Finally, we used a single hidden layer containing five units.

320 The comparison between the predictive value and the actual value in the test dataset is shown in Figure

321 4. Note: Due to the large sample size, only a part of the sample comparison chart is displayed. This is

322 also the case for the following comparison charts.
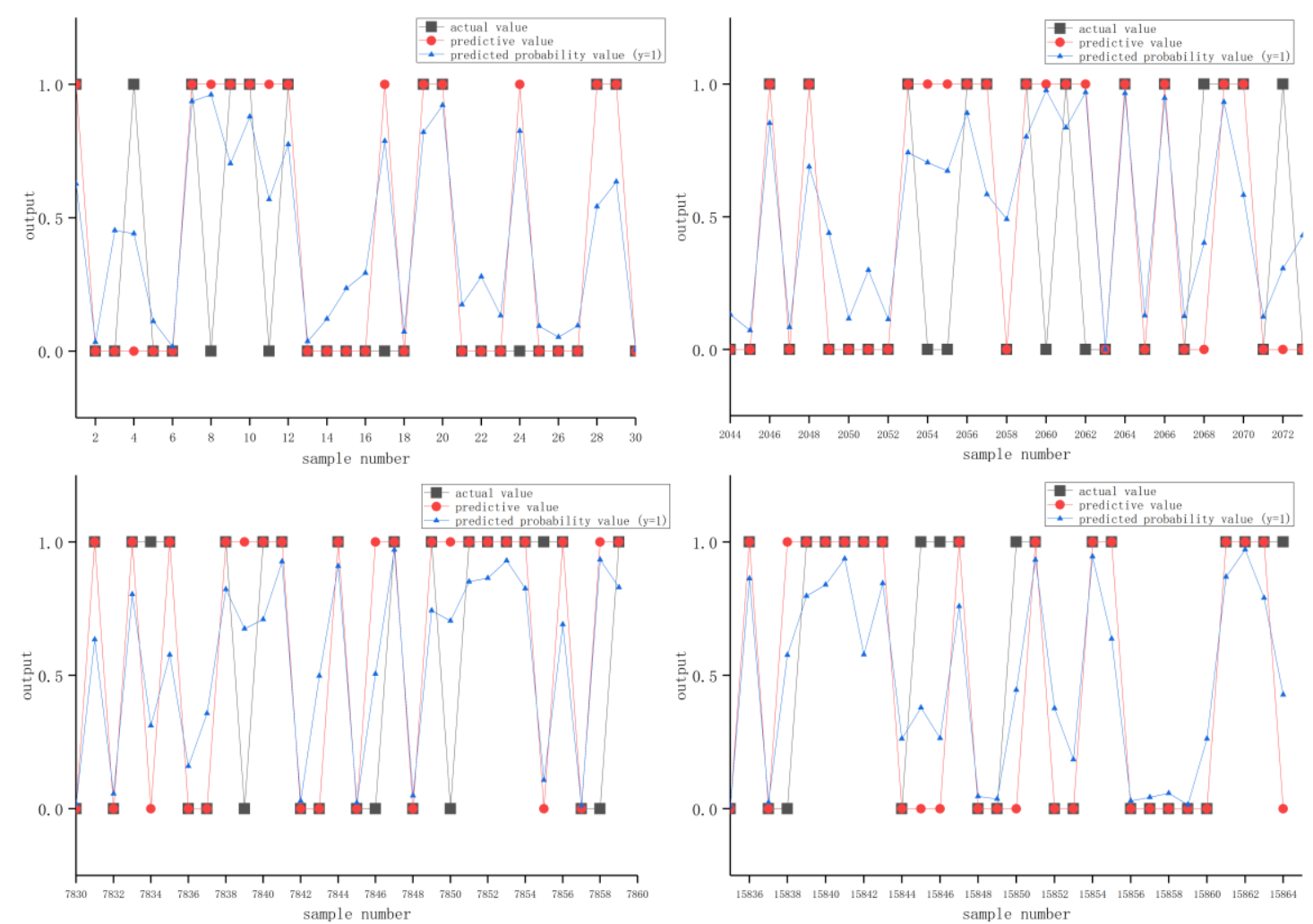


\subsubsection{Radial Basis Function Neural Network}

326 The input and output layer variables of the RBF neural network were the same as those of the ANN.

327 After training, we obtained a hidden layer containing 10 units. The comparison charts of the predictive 328 and actual values of the test set are shown in Figure 5.
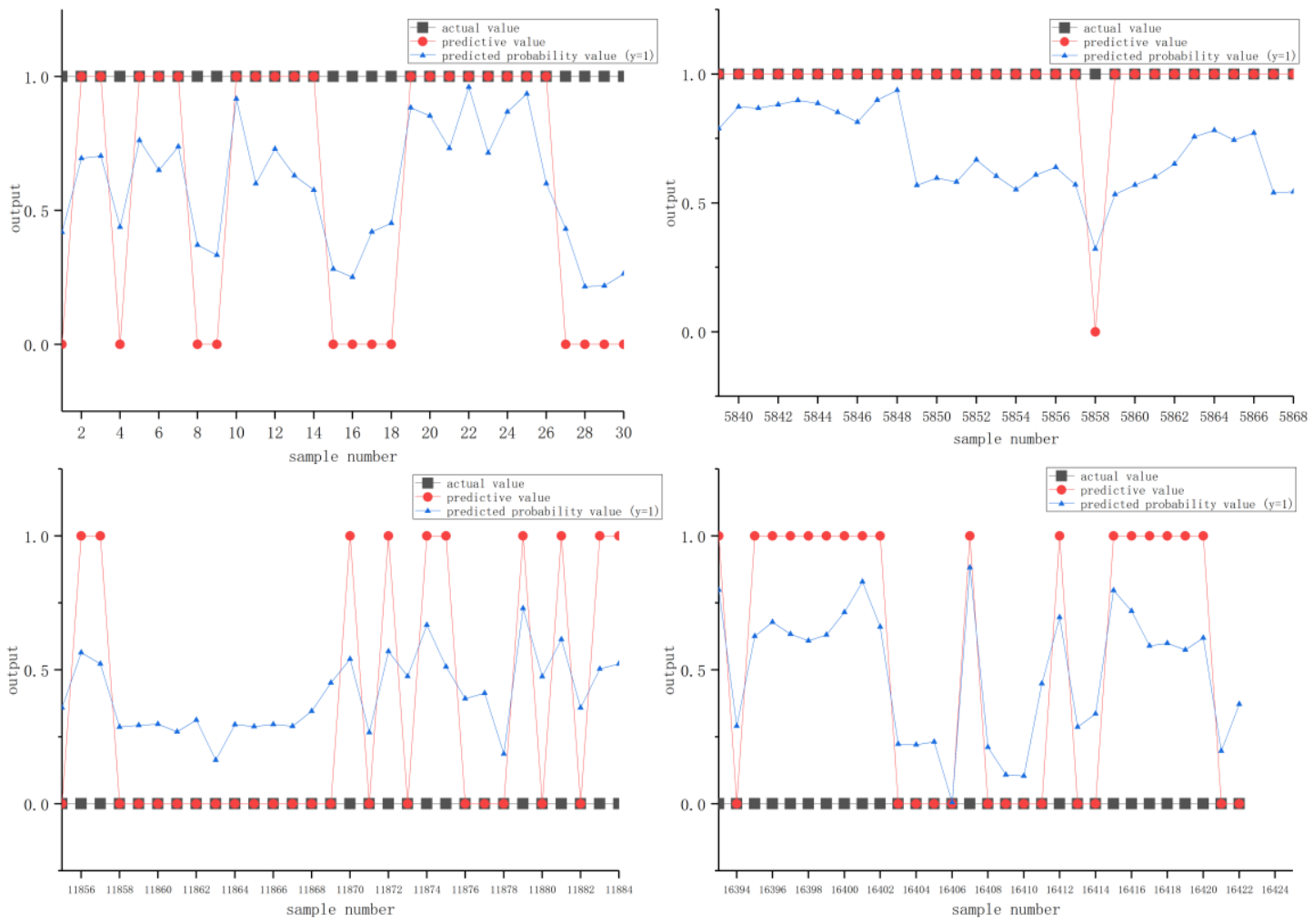

Fig. 5 Comparison charts of the predictive and actual values of the RBFN (part of the

sample)

\subsubsection{Support-Vector Machine}

We used the LIBSVM package of the MATLAB software to construct the SVM. The model was 
method and 10-fold cross validation to select parameters and determine the penalty parameter $C$ and

336 the kernel parameter $g$. Figure 6 shows a contour map and a 3D view of the result of the SVC

337 parameter selection. After calculation, the accuracy rate of the grid search method reached $83.9 \%$, and

338 the accuracy rate of cross-validation reached $82.6 \%$.

339

It can be seen from the results that the optimal values of $C$ and $g$ are 1.74 and 3.03, respectively. After

343 setting the parameters to the optimal values, we performed SVM modeling and obtained the predicted

344 values. Figure 7 shows the comparison charts of the actual and predicted values. After optimization, the

345 total number of support vectors is 19,460 , and the number of support vectors at the boundary is 17,260 .

346 After model training, the accuracy rate of the training set is $86.02 \%$, and the accuracy rate of the test set 347 is $84.27 \%$, and the performance of the model is high.

Fig 6. SVC parameter selection result: (a) contour map (b) 3D view

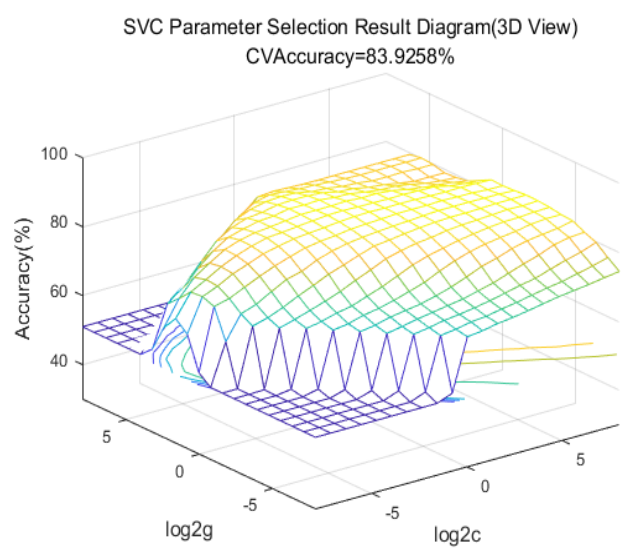

(b)

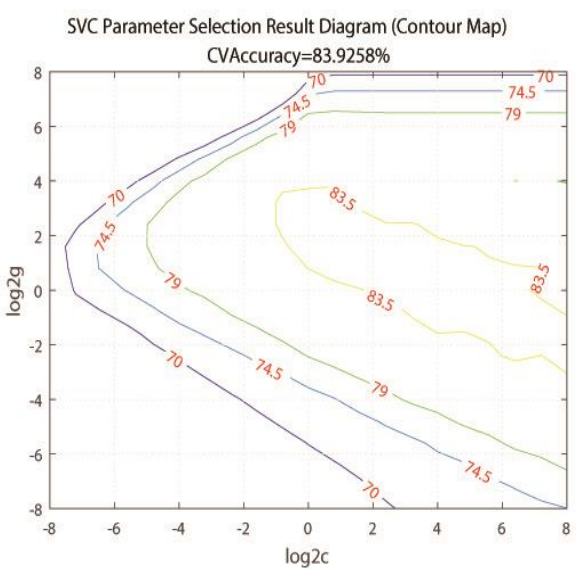

(a) 




Fig. 7 Comparison charts of the predictive and actual values of the SVM (part of the

sample)

\subsubsection{Random Forest}

We used the randomForest package in the $\mathrm{R}$ language to train random training samples. We then used cross-validation to determine the optimal parameters of the model and the number of optimal decision trees. Finally, we obtained the number of trees and the accuracy of the test and training data through cross-validation. As shown in Figure 8, when the number of decision trees is 400, the accuracy tends to be stable. We used the optimal number of decision trees to create the comparison charts of the actual and predicted values of the test set (Figure 9) and the average accuracy decline of 13 forest fire driving factors (Figure 10). It can be seen from Figure 10 that, among the main forest fire driving factors in China, the location variables that have the greatest influence on the occurrence of forest fires are longitude and latitude. Rainfall is the variable with the least influence on the occurrence of forest fires. 
The number of trees and the accuracy of training and testing in cross-validation

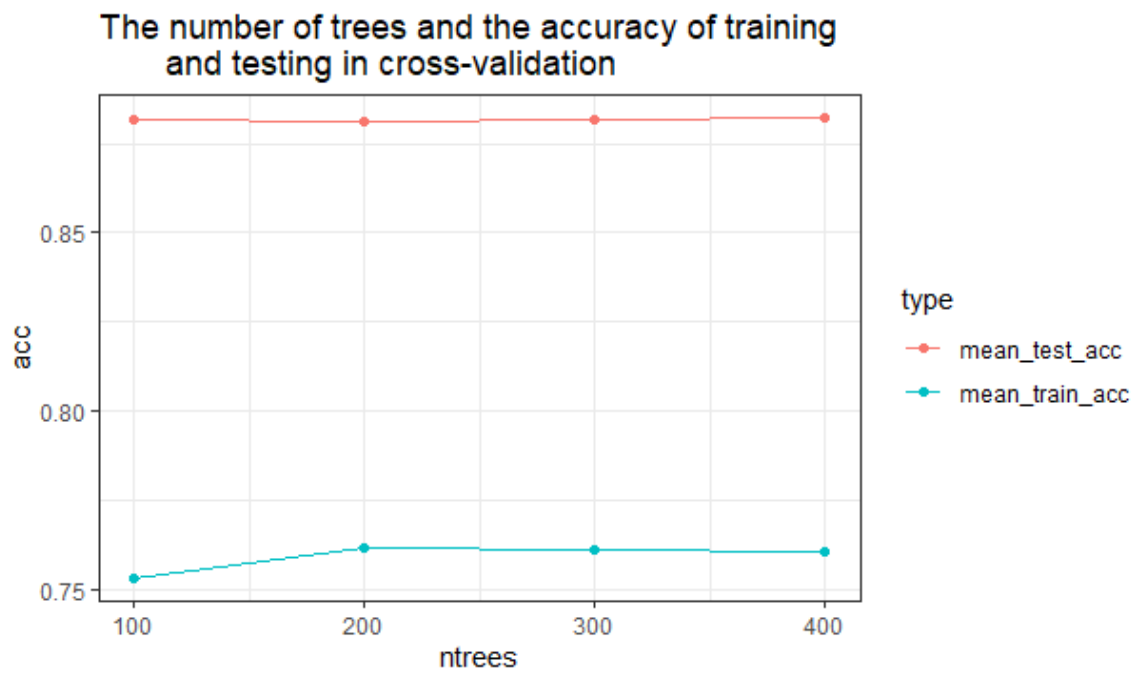

Fig. 8 The number of trees and the accuracy of training and testing in cross-validation
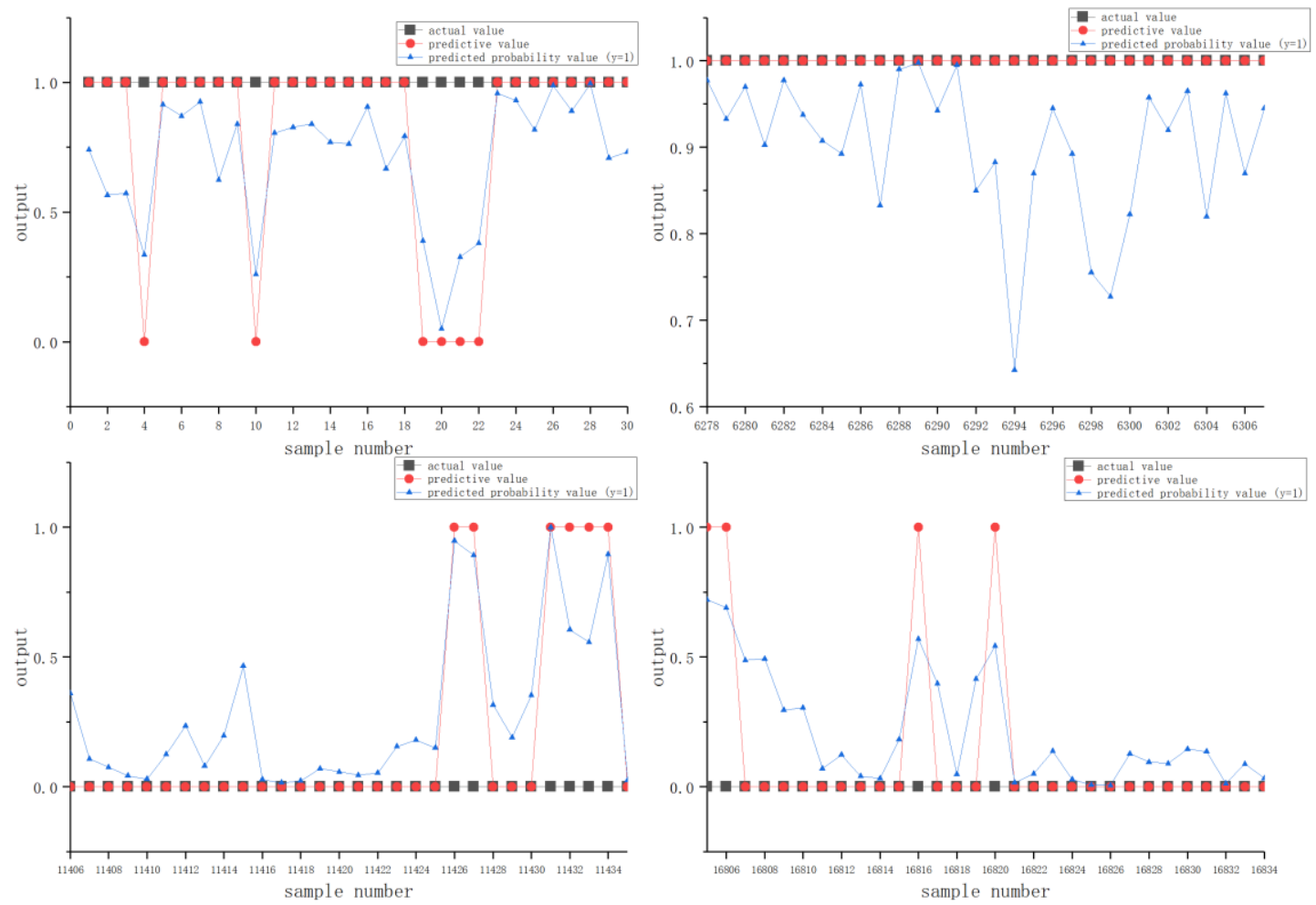

Fig. 9 Comparison charts of the predictive and actual values of the RF (part of the sample) 


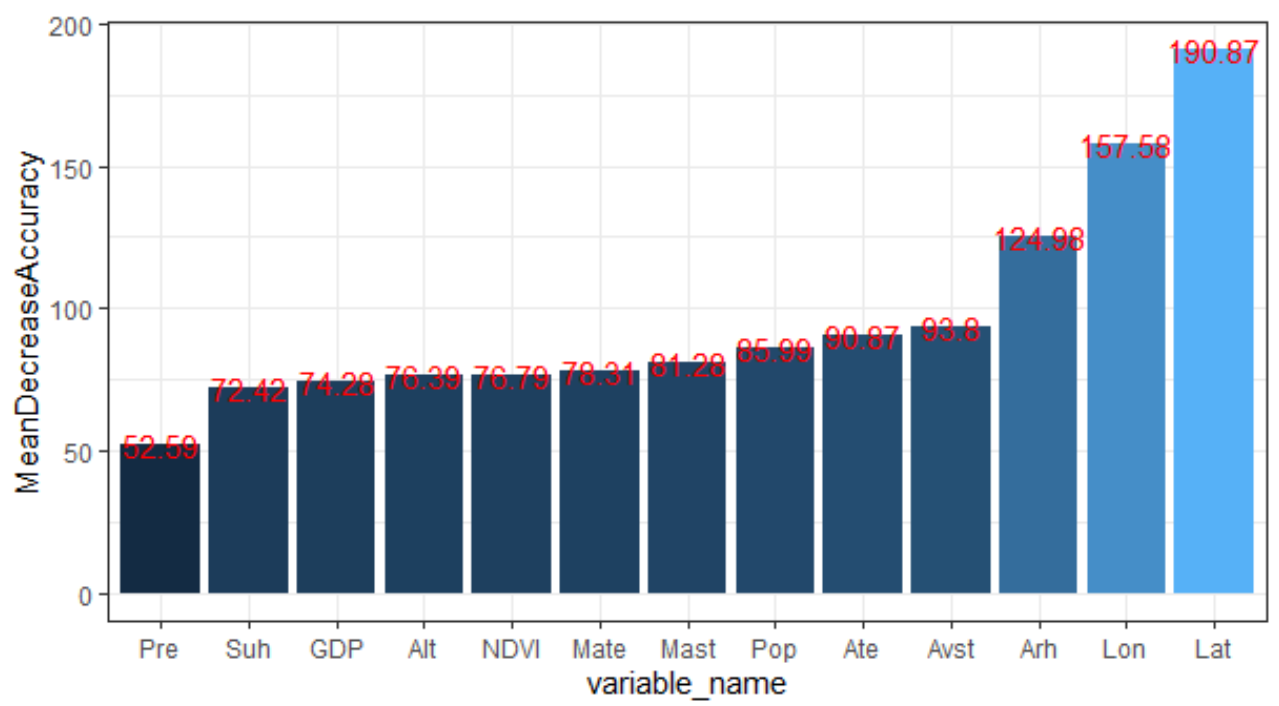

Fig. 10 Mean decrease accuracy of 13 variables

\subsection{Accuracy Evaluation}

368 We used the prediction results of the four models to construct a confusion matrix to obtain the accuracy,

369 precision, recall, f1 value, and AUC value, as shown in Table 6. Figure 11 shows the visualization of

370 the accuracy, precision, recall, and f1 values of the four models. Figure 12 shows the ROC curves of

371 the four models. The accuracy and f1 value of each model are more than $75 \%$, and the AUC value is

372 more than 0.80 . Thus, the performance of all four models is high. Among the four models, the RF

373 model has the highest predictive ability, with an accuracy rate of $89.2 \%$, an $\mathrm{f} 1$ value of $89 \%$, and the

374 highest AUC value, reaching 0.960. Compared with the other three models, the prediction ability of the

375 RBF neural network is the lowest, with an accuracy rate of $75.8 \%$ and an AUC value of 0.840 . As

376 shown in Figures 11 and 12, the RF model outperforms the other three models. We therefore consider

377 the RF model to be the most suitable of the four models for forest fire prediction in China. 


\begin{tabular}{cccccc}
\hline Model & Accuracy (\%) & Precision (\%) & Recall (\%) & $\begin{array}{c}\text { f1 value } \\
(\%)\end{array}$ & AUC \\
\hline ANN & 83.0 & 85.4 & 79.6 & 82.4 & 0.904 \\
RBFN & 75.8 & 73.1 & 81.6 & 77.1 & 0.840 \\
SVM & 84.3 & 83.0 & 86.8 & 84.8 & 0.917 \\
RF & 89.2 & 90.2 & 87.9 & 89.0 & 0.960 \\
\hline
\end{tabular}
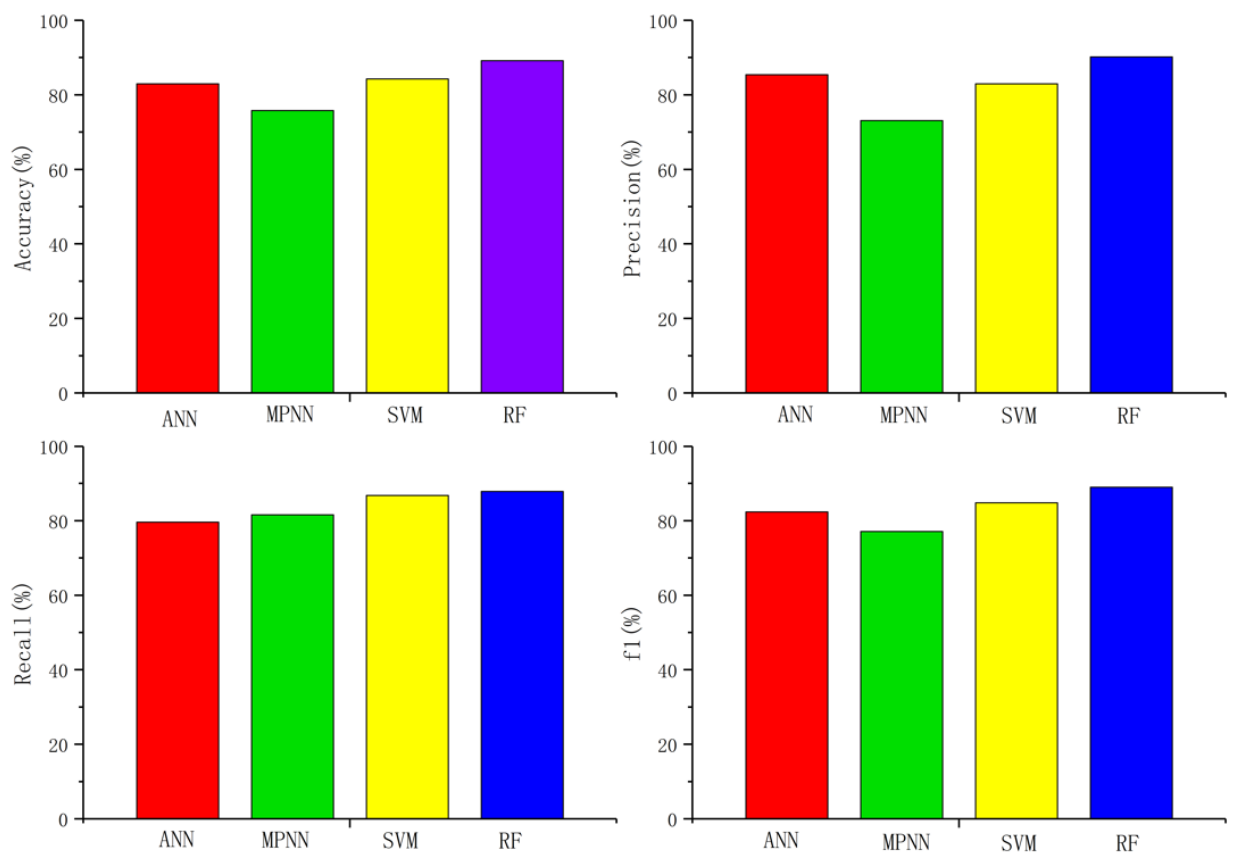

Fig 11. Comparison charts of accuracy, precision, recall, and f1 values of the four models 


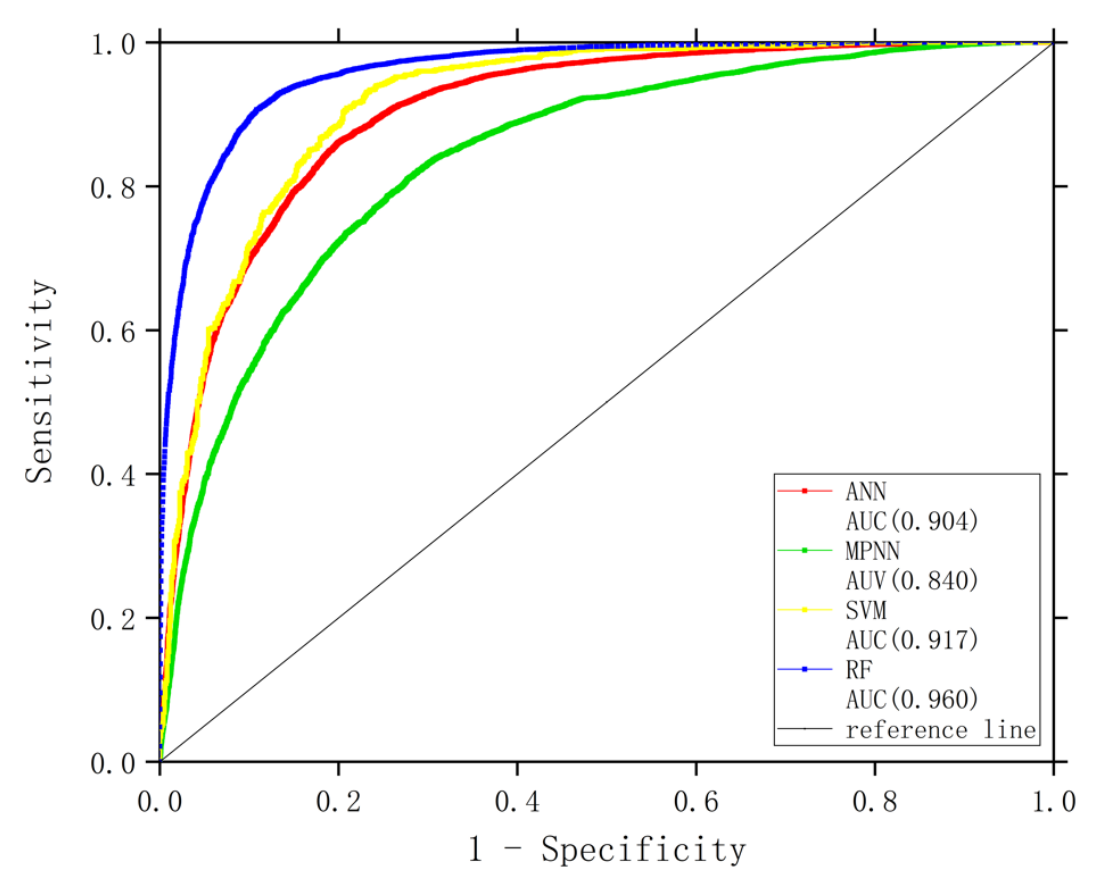

Fig. 12 ROC curves of the four models

384 After evaluating the accuracy of the four models, we used the RF model (highest accuracy) to obtain

385 the probability of forest fire occurrence for the full sample. We used ArcGIS to draw a forest fire

386 probability map (Figure 13) and a seasonal forest fire probability map (Figure 14) of China. Figure 13

387 shows that the high incidence of forest fires in China is mainly concentrated in the northeast (such as

388 the Greater Xing'an Mountains region), the southeast (such as Guangdong, Jiangxi, and Fujian), and

389 the southwest (such as Yunnan and Sichuan). On the whole, the probability of forest fires in eastern

390 China is higher than that in western regions, and the probability of forest fires in the north and south is

391 higher than that in central China. Figure 14 shows that the seasonal order of the probability of forest

392 fires in China is, from highest to lowest, spring, winter, summer, and autumn. Spring and winter are the

393 seasons with a high incidence of forest fires, which are mainly concentrated in northeast China (such as

394 Heilongjiang Province) and southeastern China (such as Fujian Province and Guangdong Province). 

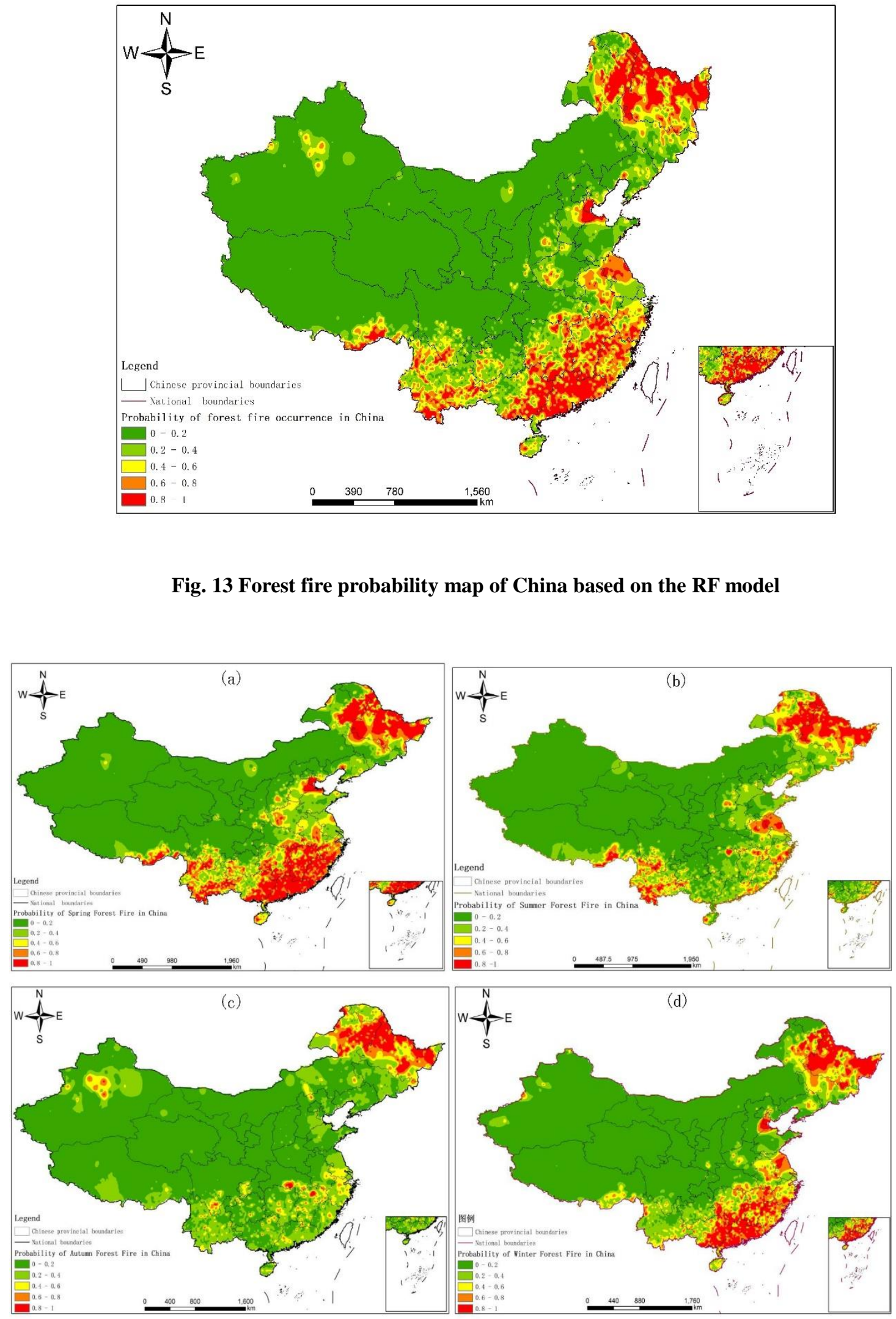

Fig. 14 Seasonal forest fire probability map of China based on the RF model: (a) spring 
401 4. Discussion

\subsection{Major Forest Fire Driving Factors in China and Their Impact}

403 are more likely to occur at certain longitudes and latitudes.

417 Climate factors also have a great impact on forest fires, which is consistent with the findings of 418 previous studies [70-73]. Temperature is one of the three necessary conditions for combustion. When

In this study, we selected over 20 factors affecting the occurrence of forest fires. These factors can be divided into six categories: location, meteorology, climate, terrain, society, and vegetation. Previous research has been conducted on the impact of these factors on forest fires [64-67]. We used the RF algorithm to filter the characteristics of these 20 forest fire driving factors and selected three or more variables in the five variable subsets as the main forest fire driving factors. In this experiment there are 13 main forest fire driving factors: longitude, latitude, average surface temperature, daily maximum surface temperature, cumulative precipitation, average relative humidity, sunshine hours, average temperature, daily maximum temperature, altitude, population, GDP, and NDVI.

\section{The results show that the location factors (longitude and latitude) are the factors that have the greatest} impact on the occurrence of forest fires. At present, there is little research that considers longitude and latitude as the main driving factors for forest fires. Some researchers, however, have confirmed that, as the latitude decreases, the number of forest fires increases [68-69]. China spans a large area, and the two factors of longitude and latitude reflect the regional differences in forest fires in China. Forest fires the temperature reaches a certain level, forest fires are more likely to occur. The longer the sunshine 
421 relative humidity are also among the main factors affecting forest fires [53][74-75].

422 Another type of driving factor is social and human factors (population and GDP). The larger the

423 population, the greater the human activity in the region and the more likely it is that human factors

424 cause forest fires. Catry et al. [76] (2007)and Sepulveda[77] (2001)reached the same conclusion.

425 Altitude and vegetation (NDVI) also affect the occurrence of forest fires to varying degrees. Tian et al.

426 [78] contend that forest fires mainly occur in low-altitude areas (2013). Chuvieco et al. [79] used NDVI

427 as a driving factor for forest fires to estimate fuel moisture (2004). The greater the NDVI value, the

428 higher the vegetation coverage; and the greater the flammability of the tree species, the more likely

429 such trees are to cause problems related to forest fires.

430 In this study, we used a RF algorithm for feature selection and eliminated seven variables: average

431 wind speed, maximum wind speed, aspect, slope, distance from fire point to highway, closest distance

432 from fire point to residential area, and special festivals. In this experiment, these factors have little

433 effect on the occurrence of forest fires. It may be that these factors change with time and space,

434 however. Other studies have found that these factors are among the main drivers of forest fires[80][81].

435 We believe that this may be due to the difference in the selected data and the difference in the method

436 of feature selection. In future research, a variety of feature-screening methods and analysis of different

437 regions may be used to obtain more comprehensive results.

$438 \quad$ 4.2 Optimal Choice of Forest Fire Prediction Model

439 We entered the forest fire driving factors selected by feature selection into the four models (ANN, RBF

440 neural network, SVM, and RF) for training. We then evaluated them using five criteria: accuracy, 
441 precision, recall rate, f1 value, and AUC value. We selected the RF model as the optimal choice for

442 forest fire prediction. The accuracies of all four models are above $75 \%$, which means that they are all

443 reliable. The RF model, however, exhibits the greatest prediction ability. The RBF neural network

444 model has the lowest prediction performance.

445 Samaher et al. [25] used a cascade correlation network, multilayer perceptron neural network,

446 polynomial neural network, RBF, and SVM for forest fire prediction(2018). They found the prediction

447 performance of the SVM was the highest, and the performance of RBF was the lowest, which is

448 consistent with our conclusion. Sakr et al. [36] used an SVM and an ANN to predict the fire risk in

449 Lebanon (2011). Their results showed that the performance of the SVM model was higher than that of

450 the ANN model. This finding is similar to ours. Paulo et al. [8] used RF and SVM models to predict

451 forest fires (2007). They concluded that the performance of the SVM model was higher than that of the

452 RF. Their finding is different from our results. A possible reason for this difference is that Paulo et al.

453 chose four types of weather factors and made predictions about small areas, whereas we chose 13 types

454 of factors and made predictions about a large area. The choice of variables and the difference in the

455 sample size affect the model training.

456 Bisquert et al. [82] used an ANN to establish a forest fire hazard model with a highest accuracy rate of

$45776 \%$, which is lower than the accuracy of our model (83\%) (2012). Hong [83] used an SVM algorithm

458 to analyze Dayu County in southwestern Jiangxi Province, China (2018). The results show that the

459 AUC value of the SVM is 0.75, which is lower than the value in our model (0.92). Pourtaghid et al.[45]

460 used an RF to create forest fire sensitivity analysis with a prediction accuracy of $72.8 \%$ (2016). Our

461 model reached a prediction accuracy of $89.2 \%$. 
The four models we selected all exhibit high predictive capabilities. The main reason may be that appropriate multi-dimensional variables has been screened out and the data sample size is large, which makes the training of each model more accurate and reliable.

There are also differences in the characteristics of these four models. The ANN and RBF neural network models can be trained very quickly, and they can handle samples with a large amount of data, but their accuracy in this experiment is relatively low. In subsequent studies, particle swarms or genetic algorithms could be used to improve the accuracy of these models. The SVM model has a high predictive ability, but it also has shortcomings. The higher the model complexity, the lower the calculation speed. It takes a longer time in this model to obtain the optimal parameters when processing large sample data. We will consider using other algorithms to optimize SVM in the future. The RF model exhibited excellent expressive power in this experiment. It can quickly process large data samples while ensuring high prediction accuracy.

\subsection{Recommendations for Forest Fire Prevention}

We produced a probability map of forest fires in China that shows that the highest incidences of forest fires are in the northeast (Heilongjiang Province and the northern Inner Mongolia Autonomous Region), the southeast (Fujian Province, Guangdong Province, and Jiangxi Province), and Yunnan Province. The pattern of forest fire points presents a spatial clustering distribution. Ma et al. obtained similar results [4]. For these high-incidence areas, watch towers and monitoring equipment should be added for monitoring and management. Moreover, the length of the forest fire barrier net should be increased to reduce the spread of fires. In addition, the number of fire brigades and fire vehicles should be increased to enhance the disaster-mitigation capabilities. Regarding seasonal risks of forest fires, forest fire 
prevention and control should be emphasized in spring and winter. Strengthening fire-prevention management during these periods would mainly involve strengthening the management of human activities to reduce human-made forest fires and improving publicity and education, such as the addition of fire-prevention signs.

This study has some shortcomings, and there is scope for improvement. One of the three elements of fire is combustible fuel. For the selection of forest fire driving factors, however, there is currently no way to obtain data on fuel load and other related factors. Thus, this experiment lacked relevant data such as combustible load, particle size of combustible material, and combustible tree species. If possible, in future research, such data could be added to the forest fire prediction model.

This study selected four kinds of machine-learning algorithms for the forest fire prediction model.

Other applicable machine-learning algorithms could be used in future experiments. In addition, the ability of these machine-learning algorithms to analyze spatial heterogeneity is relatively weak. Subsequent research could use geographically weighted regression to build a high-precision forest fire prediction model.

\section{Conclusion}

This study determined the main driving factors of forest fire occurrence in China through feature selection. The main factors that affect the occurrence of forest fires to varying degrees are meteorological, topographic, man-made, and vegetation factors. We built four forest fire prediction models using the following machine-learning algorithms: an artificial neural network, a radial basis function neural network, a support-vector machine, and a random forest. The results of the evaluation 
504 fire prediction models. Among the four models, the RF model has the highest comprehensive predictive

505 ability, with an accuracy of $89.25 \%$. It is therefore the optimal choice for a forest fire prediction model

506 in China.

507 We used the RF model to predict the probabilities of forest fires in China. Based on these probabilities,

508 we drew a map of the probability of forest fire occurrence in China and a map of the probability of

509 forest fires in China by season (spring, summer, autumn, and winter). Finally, based on these maps, we

510 identified the high-incidence areas and areas at risk of forest fires. We then put forward fire-prevention

511 recommendations for the corresponding regions and seasons.

512 This research helps in understanding the main forest fire driving factors in China. It provides a

513 reference for the selection of high-precision forest fire prediction models. In addition, it provides

514 suggestions on the time and location of forest fire prevention in China. Moreover, this study provides

515 guidance for China's forest fire prevention and control work.

\section{Data Availability}

517 The data used to support the findings of this study are available from the corresponding author upon

518 request.

\section{Conflicts of Interest}

520 The authors declare that they have no conflicts of interest. 
521 Funding Statement

522 This research was jointly supported by the medium long-term project of "Precision Forestry Key

523 Technology and Equipment Research" (No. 2015ZCQ-LX-01) and the National Natural Science

524 Foundation of China (No. U1710123).

\section{Authors' contributions}

526 Yudong Li performed the experiment and wrote the manuscript;

527 Zhongke Feng contributed to the conception of the study;

528 Ziyu Zhao and Shilin Chen helped perform the analysis with constructive discussions;

529 Hanyue Zhang helped perform the data analysis.

\section{Acknowledgments}

531 We would like to acknowledge support from Beijing Key Laboratory for Precision Forestry, Beijing

532 Forestry University, as well as all the people who have contributed to this paper.

\section{References}

534 [1] Bhusal, Satish \& Mandal, Ram. (2020) Forest fire occurrence, distribution and future risks in 535 Arghakhanchi district, Nepal. Journal of Geography. 2(1):10-20.

536 [2] B. K. Singh, N. Kumar and P. Tiwari. (2019) "Extreme Learning Machine Approach for Prediction of Forest Fires using Topographical and Metrological Data of Vietnam," 2019 Women Institute of Uttarakhand, India,. pp. 104-112. doi: 10.1109/WITCONECE48374.2019.9092926.

540 [3] D Mandallaz, R Ye. (1997) Prediction of forest fires with Poisson models, Canadian Journal of 
Forest Research. 27(10): 1685-1694.https://doi.org/10.1139/x97-103.

542 [4] Ma, W., Feng, Z., Cheng, Z., Chen, S., \& Wang, F. (2020) Identifying Forest Fire Driving Factors

543 and Related Impacts in China Using Random Forest Algorithm. Forests. 11(5), 507.

544 doi:10.3390/f11050507.

545 [5] Dimopoulou, M.; Giannikos, I. (2004) Towards an integrated framework for forest fire control.

$546 \quad$ Eur. J. Oper. Res. 152: 476-486.

547 [6] Flannigan, M.D.; Krawchuk, M.A.; Groot, W.J.D.; Wotton, B.M.; Gowman, L.M. (2009)

548 Implications of changing climate for global wildland fire. Int. J. Wildland Fire. 18:483-507.

549 [7] Z. Q. Xu, X. Y. Su, Y. Zhang. (2012) Forest Fire Prediction Based on Support Vector Machine.

550 Chinese Agricultural Science Bulletin.28(13):126-131.

551 [8] Paulo Cortez, Anibal Morais. (2007) A Data Mining Approach to Predict Forest Fires using Meteorological Data. New Trends in Artificial Intelligence. 512-523.

553 [9] Barik A, Baidya Roy S. (2020) Effects of meteorology on forest fires in India: A modeling 554 study[C]//EGU General Assembly Conference Abstracts. 18317.

555 [10] Chetehouna K. (2020) Overview of The Forest Fire Research[C]//Proceeding International $556 \quad$ Conference on Science and Engineering. 3: xvii-xvii.

557 [11] Shang C, Wulder M A, Coops N C, et al. (2020) Spatially-Explicit Prediction of Wildfire Burn 558 Probability Using Remotely-Sensed and Ancillary Data. Canadian Journal of Remote Sensing. $1-17$.

560 [12] Z.W. SU, A.Q. LIU et al. (2016) Driving factors and spatial distribution patteren of forest fire in 561 Fujian Province. JOURNAL OF NATURAL DISASTERS. 25(2):110-119.

562 [13] M. Yu, (2016) The establishment and study of Regional forest fire prediction and forecasting 
model. Beijing, Beijing Forestry University.

564 [14] Y. Song. (2018) Research on Forest Fire Drivers and Models in Heilongjiang Province. Herbing, Northeast Forestry University.

566 [15] CV Garcia, PM Woodard, SJ Titus, WL Adamowicz and BS Lee. (1995) A Logit Model for Predicting the Daily Occurrence of Human Caused Forest-Fires. International Journal of Wildland Fire. 5(2):101-111.

[16] H. Peng , M.C. Shi , Y. Sun, Mike Wotton. (2014) Lightning Fire Forecasting Model of Daxing'an Mountain Based on Logistic Model. Journal of Northeast Forestry University. 42(7):166-169.

[17] W.G. Wang, J.H. Pan, Y.Y Feng, Z. Li, L. L. Dong. (2017) Model and Zoning of Fire Risk in Gansu Province based on GWLR and MODIS Imagery. Remote Sensing Technology and Application. 32(03):514-523.

[18] Futao Guo, Selvara Selvalakshmi, Fangfang Lin, Guangyu Wang, Wenhui Wang, Zhangwen Su, Aiqin Liua.(2016)Geospatial information on geographical and human factors improved anthropogenic fire occurrence modeling in the Chinese boreal forest. Canadian Journal of Forest

[19] K.Z. Liu, L.F. Shu, F.J. Zhao et al. (2017) Research on spatial distribution of forest fire based on satellite hotspots data and forecasting model. Journal of Forestry Engineering, 2:128-133.

[20] B.Q. LIAO, J. WEI et al. (2008) Logistic and ZIP Regression Model for Forest Fire Data. FIRE SAFETY SCIENCE.3:143-149.

582 [21] D Mandallaz, R Ye. (1997) Prediction of forest fires with Poisson models. Canadian Journal of Forest Research.27(10): 1685-1694. https://doi.org/10.1139/x97-103.

584 [22] F.T. GUO, H.Q. HU et al. (2010) Relationship between forest lighting fire occurrence and weather 
factors in Daxing'an Mountains based on negative binomial model and zero-inflated negative binomial models. Chinese Journal of Plant Ecology.21(01):159-164.

587 [23] H.L. Liang ,Y.R. Lin, G. Yang et al. (2016) Application of Random Forest Algorithm on the Forest Fire Prediction in Tahe Area Based on Meteorological Factors. SCIENTIA SILVAE SINICAE.52(01):89-98.

[24] Z.Q. Xu. (2012) Forest Fire Area Prediction Based on Support Vector Machine. Beijing, Beijing Forestry University.

[25] Samaher Al_Janabia et al. (2018) Assessing the suitability of soft computing approaches for forest fires prediction. Applied Computing and Informatics. (14): 214-224.

[26] Volkan Sevinca, Omer Kucukb, Merih Goltasc. (2020) A Bayesian network model for prediction and analysis of possible forest fire causes. Forest Ecology and Management. (457):1-11.

596 [27] T. Artés, A. Cencerrado, A. Cortés, T. Margalef. (2016) Time aware genetic algorithm for forest fire propagation prediction: exploiting multi-core platforms, Concurrency and Computation: Practice and Experience.

[28] D.T. Bui, Q.T. Bui, Q.P. Nguyen, B. Pradhan, H. Nampak, P.T. Trinh, (2017) A hybrid artificial intelligence approach using GIS-based neural-fuzzy inference system and particle swarm optimization for forest fire susceptibility modeling at a tropical area, Agric. For. Meteorol. 233: $32-44$

[29] M. Denham, A. Cortés, T. Margalef, E. Luque, (2008) Applying a dynamic data driven genetic algorithm to improve forest fire spread prediction. International Conference on Computational Science. Springer Berlin Heidelberg. pp.36-45. 
610 [31] A.M. Özbayog ־lu, R. Bozer, (2012) Estimation of the burned area in forest fires using

611 computational intelligence techniques, Proc. Comput. Sci. $12: 282-287$.

612 [32] H. Soliman, K. Sudan and A. Mishra. (2010) A smart forest-fire early detection sensory system:

613 Another approach of utilizing wireless sensor and neural networks. SENSORS, 2010 IEEE, Kona, HI. pp. 1900-1904.doi: 10.1109/ICSENS.2010.5690033.

615 [33] Çetin Elmas, Yusuf Sönmez. (2011) A data fusion framework with novel hybrid algorithm for multi-agent Decision Support System for Forest Fir. Expert Systems with Applications.38(8):9225-9236. https://doi.org/10.1016/j.eswa.2011.01.125.

618 [34] Onur Satir, Suha Berberoglu \& Cenk Donmez (2016) Mapping regional forest fire probability using artificial neural network model in a Mediterranean forest ecosystem, Geomatics. Natural Hazards and Risk. 7: 1645-1658, doi: 10.1080/19475705.2015.1084541.

621 [35] Maeda, E. E., Formaggio, A. R., Shimabukuro, Y. E., Arcoverde, G. F. B., \& Hansen, M. C. (2009). Predicting forest fire in the Brazilian Amazon using MODIS imagery and artificial neural networks. International Journal of Applied Earth Observation and Geoinformation, 11(4), 265272. doi: 10.1016/j.jag.2009.03.003.

625 [36] Sakr G E, Elhajj I H, Mitri G. (2011) Efficient forest fire occurrence prediction for developing countries using two weather parameters. Engineering Applications of ArtificialIntelligence.24(5): 888-894.

628 [37] B.C. Ko, K.H. Cheong, J.Y. Nam. (2009) Fire detection based on vision sensor and support vector 
machines. Fire Saf. J. 44 (3): 322-329.

630 [38] G.E. Sakr, I.H. Elhajj, G. Mitri, Efficient forest fire occurrence prediction for developing countries

631 using two weather parameters. Eng. Appl. Artif. Intell. 24.

632 [39] D.W. Xie, S.L. Shi,(2014)Prediction for burned area of forest fires based on SVM model, in: Applied Mechanics and Materials. Trans Tech Publications. 513(5):4084-4089.

634

[40] J. Zhao, Z. Zhang, S. Han, C. Qu, Z. Yuan, D. Zhang. (2011) SVM based forest fire detection using static and dynamic features. Computer Sci. Inform. Syst. 8(3): 821-841.

636 [41] Cutler DR, et al. (2007) Random forests for classification in Ecology. Ecology.88(11):2783-2792.

637 [42] Prasad AM, et al. (2006) Newer classification and regression tree techniques: Bagging and random forests for ecological prediction. Ecosystems .9(2):181-199.

639 [43] Rodrigucs M, Dc la Riva J. (2014) An insight into machines learning algorithms to model humarrcaused wildfire or currence. Environmental Modelling \& Software,57:192-201.

641 [44] LIANG H L, LIN Y R, YANG G, et al.(2016) Application of random forest algorithm on the forest fire prediction in Tahe area based on meteorological factors. Scientla Silvae Sinicae.52(1):89-98.

644 [45] Pourtaghi, Z. S., Pourghasemi, H. R., Aretano, R., \& Semeraro, T. (2016) Investigation of general techniques. Ecological Indicators. 64:72-84. doi:10.1016/j.ecolind.2015.12.030.

647 [46] Tian, X., Zhao, F., Shu. L. (2013) Wang, M. Distribution characteristics and the influence factors of forest fires in China. For. Ecol. Manag. 310:460-467. mean number of forest fires and mean forest area burned (1987-2007) in China. For. Ecol. Manag. 
652 [48] Zhong. M., Fan, W., Liu. T., Li. P. (2003) Statistical analysis on current status of China forest fire 653 safety. Fire Saf. J. 38:257-269.

654 [49] Aifeng, L.U. (2011) Study on the relationship among forest fire, temperature and precipitation and its spatial-temporal variability in China. Agric. Sci. Technol. 12:1396-1400.

656 [50] Ying. L., Han. J., Du. Y., Shen, Z. (2018) Forest fire characteristics in China: Spatial patterns and determinants with thresholds. For. Ecol. Manag.424:345-354.

658 [51] X.K. Ren, Chinese Geography, Chinese Press, ISBN:9787507528800.

659 [52] F.T. Guo, Z.W. Su, G.Y. Wang et al. (2017) Understanding fire drivers and relative impacts in different Chinese forest ecosystems. Science of the Total Environment.605: 411-425.

661 [53] GUO F, WANG G, SU Z, et al. (2016) What drives forest fire in Fujian, China? Evidence from logistic regression and random forests. International Journal of Wildland Fire.25(5):505-519.

663 [54] Chang Y, Zhu Z L, Bu R C, et al. (2013) Predicting fire occurrence pat-terns with logistic regression in Heilongjiang Province, China. Landscape Ecology.28(10) : 1989 -2004 .

665 [55] XU X L. (2018) Spatial distribution data set of quarterly vegetation index (NDVI) in China. Data Chinese Academy of Sciences (http://www.resdc.cn/DOI).

668 [56] W.Y MA, Z.K. FENG et al. (2020) Study on driving factors and distribution pattern of forest fires in Shanxi province. Journal of Central South University of Forestry \& Technology.1-13.

670 [57] ERIDUNTONGLAGA. (2013) Analysis on landscape pattern of woodland based on DEM in the Daqingshan Mountains Inner Mongolia. Huhhot: Inner Mongolia Normal University.

672 [58] A. Subasi, (2007) EEG signal classification using wavelet feature extraction and a mixture of 
674 [59] D. Chen. (2019) Prediction of Forest Fire Occurrence in Daxing'an Mountains Based on Logistic Regression Model," FOREST RESOURCES MANAGEMENT. (01):116-122.

676 [60] Q.Q. Wang, J.T. Tong, L. Zhang et al. (2020) Seismic data denoising using multi-layer perceptron. Oil Geophysical Prospecting.55(02):272-281+228.

[61] D.S. Broomhead, D. Lowe, (1988) Radial basis functions, multi-variable functional interpolation and adaptive networks (No. RSRE-MEMO-4148). Royal signals and radar establishment Malvern (United Kingdom).

[62] X.C. Wang et al. (2013) 43 Cases of MATLAB neural network analysis. Beijing, Bei hang University Press.

[63] Yudong Li, Zhongke Feng, Shilin Chen, Ziyu Zhao, and Fengge Wang. (2020) Application of the Artificial Neural Network and Support Vector Machines in Forest Fire Prediction in the Guangxi Autonomous Region, China. Discrete Dynamics in Nature and Society. https://doi.org/10.1155/2020/5612650.

[64] Ganteaume A, Camia A, Jappiot M, et al. (2013) A review of the main driving factors of forest fire ignition over Europe. Environmental Management. 51(3): 651-662. Predicting spatial patterns of fire on a southern California landscape. Int J Wildland Fire 17:602613. wildfires in the temperate rainforest of Vancouver Island, Canada. Forest Ecol Manag 140:1-18.

694 [67] Dickson BG, Prather JW, Xu Y, Hampton HM, Aumack EN, Sisk TD (2006) Mapping the 
probability of large fire occurrence in northern Arizona. USA Landsc Ecol 2:747-761.

696 [68] Ying. L., Han. J.; Du. Y., Shen, Z. (2018) Forest fire characteristics in China: Spatial patterns and determinants with thresholds. For. Ecol. Manag. 424:345-354.

[69] Prasad, A.M.; Iverson, L.R.; Liaw, A. (2006) Newer classification and regression tree techniques: Bagging and random forests for ecological prediction. Ecosystems. 9:181-199.

[70] Guo F, Su Z, Wang G, et al. (2016) Wildfire ignition in the forests of southeast China: Identifying drivers and spatial distribution to predict wildfire likelihood. Applied Geography. 12-21.

702 [71] Liu, Z., Yang, J., Chang, Y., Weisberg, P. J., \& He, H. S. (2012). Spatial patterns and drivers of fire occurrence and its future trend under climate change in a boreal forest of northeast China. Global Change Biology, 18:2041-2056.

[72] Syphard, A. D., Radeloff, V. C., Keuler, N. S., Taylor, R. S., Hawbaker, T. J., Stewart, S. I., et al. (2008) Predicting spatial patterns of fire on a southern California landscape. International Journal

[73] Ying L, Han J, Du Y, et al. (2018) Forest fire characteristics in China: Spatial patterns and of Wildland Fire.17:602-613. determinants with thresholds. Forest Ecology and Management.345-354.

[74] Zumbrunnen, T., Pezzatti, G. B., Men?endezd, P., Bugmann, H., Bürgi, M., \& Conedera, M. (2011)

711 Weather and human impacts on forest fires: 100 years of fire history in two climatic regions of Switzerland. Forest Ecology and Management.261:2188-2199.

713 [75] Cardille J A, Ventura S J, Turner M G, et al. (2001) ENVIRONMENTAL AND SOCIAL 
Portugal. Available at: http://www. eufirelab.org/toolbox2/library/upload/2380.pdf, 2009-08.

718 [77] Sepulveda B J I, Meza S R, Zuniga C W R et al. (2001) GIS to Determine Risk of Forest Fires in Northwestern Mexico. Mexico: Technical Publication. 37.

720 [78] Tian, X.; Zhao, F.; Shu, L.; Wang, M. (2013) Distribution characteristics and the influence factors of forest fires in China. For. Ecol. Manag. 310: 460-467.

[79] Chuvieco, E.; Cocero, D.; Riaño, D.; Martin, P .; Martínez-Vega, J.; de la Riva, J.; Pérez, F. (2004) Combining ndvi and surface temperature for the estimation of live fuel moisture content in forest fire danger rating. Remote Sens. Environ. 92: 322-331.

[80] Maingi K J, Henry M C. (2007) Factors influencing wildfire occurrence and distribution in eastern Kentucky, USA. International Journal of Wildland Fire, 16(1): 23-33. doi: 10.1071/ WF06007.

727 [81] Avilaflores D Y, Pompagarcia M, Antonionemiga X, et al. (2010) Driving factors for forest fire 728 occurrence in Durango State of Mexico: A geospatial perspective. Chinese Geographical Science. 20(6): 491-497.

730 [82] Bisquert M, Caselles E, Sanchez J M, et al. (2012) Application of artificial neural networks and logistic regression to the prediction of forest fire danger in Galicia using MODIS data.

733 [83] Hong, H., et al., (2018) Applying genetic algorithms to set the optimal combination of forest fire 734 related variables and model forest fire susceptibility based on data mining models. The case of 735 Dayu County, China. Science of The Total Environment. 630:1044-1056. 